\title{
Desarrollo de un modelo de detección, prevención y tratamiento del maltrato infantil a partir del sistema escolar ${ }^{1}$
}

\author{
Ps. Soledad Larrain H. ${ }^{2}$ \\ Ps. Gabriela Sepúlveda
}

\begin{abstract}
Resumen
Este artículo propone un modelo interdisciplinario de detección, evaluación, prevención y atención de niños con evidencia o sospecha de maltrato y de su grupo familiar a través del sistema escolar. Se desarrolló una pauta de detección de maltrato infantil para ser aplicada por profesores $\mathrm{y} / \mathrm{o}$ orientadores y se desarrollaron talleres para niños, padres y profesores desde un enfoque cognitivo.

La evaluación psicológica del desarrollo afectivo-social de los niños con sospecha de maltrato muestra predominio de imágenes negativas de si mismo y del mundo, relaciones interpersonales insatisfactorias, expresión de tristeza, bajo control de impulsos, necesidades básicas insatisfechas, bajo nivel de desarrollo moral y de resolución de problemas interpersonales.

Se concluye que siguiendo los pasos establecidos en el modelo propuesto, es posible desarrollar un programa preventivo de maltrato infantil en la comunidad, partiendo desde el sistema escolar, en donde los profesores, previamente capacitados tienen un rol de liderazgo en el trabajo con niños y padres.
\end{abstract}

\begin{abstract}
This paper proposes an interdisciplinary model of detection, evaluation, prevention and treatment of children with evidence or suspect of abuse, and their family group, through the school system. It was designed an instrument to detect child abuse, to be applied by teachers and/or counselors. There were developed and applied Workshops, from a cognitive approach, for children, parents and teachers.

The psychological evaluation of affective and social development of children suspect of abuse, shows a predominance of negative images of self and of the world, unsatisfactory interpersonal relationships, low level of both moral development and interpersonal problem solving.

It is concluded that following the steps established in the proposed model, it is possible to develop a preventive program of child abuse in the community, starting from the school system, in which the teachers, previously trained, have a leadership role in the work with children and parents.
\end{abstract}

Key words: Violence, treatment, prevention

\section{Introducción}

En Chile, en los últimos años se han producido importantes avances en el ámbito institucional orientados a abordar el problema del maltrato infantil. Se ha aprobado una nueva legislación, se ha implementado un programa nacional desde el Ministerio de Salud, se ha trabajado en la coordina-

\footnotetext{
${ }^{1}$ Este proyecto fue realizado con financiamiento de FONDECYT.

${ }_{2}^{2}$ Psicólogas, Departamento de Psicología, Facultad de Ciencias Sociales, Universidad de Chile.
} 
ción intersectorial a través de la Comisión Intersectorial de Prevención del Maltrato Infantil, SENAME posee un programa especificamente orientado a los niños víctimas de maltrato y abuso sexual y existen importantes iniciativas en distintas regiones del país.

Sin embargo junto con los avances legales y de centros de atención a víctimas de maltrato, es fundamental avanzar en la implementación de políticas de prevención y de detección temprana del problema. En ambas situaciones el sistema escolar es un espacio privilegiado tanto para la detección temprana del maltrato, como para la implementación de politicas de prevención.

En el presente artículo se describe una experiencia de diseño, implementación y evaluación de un programa de detección e intervención en maltrato infantil para ser implementado a partir del sistema escolar. (1995-97)

La etapa de diseño, implementación y evaluación se realizó en la Comuna de Peñalolen y la etapa de reproducción (tercer año) se realizó en la comuna de ElBosque.

\section{El Maltrato Infantil en Chile:}

En los últimos años se ha comenzado a plantear a la opinión pública la gravedad del maltrato infantil en Chile. Cada cierto tiempo conocemos de situaciones graves de maltrato a niños por parte de sus padres o cuidadores; sin embargo aún existen muy pocos antecedentes que nos permitan decir con exactitud cual es la dimensión del maltrato en nuestro país.

En la actualidad no hay evidencias que permitan dar respuesta a estas interrogantes, sin embargo, las investigaciones realizadas en la última década permiten afirmar las siguientes características de la situación de maltrato en Chile.

- A pesar del subregistro existente, el maltrato infantil constituye un porcentaje importante de la demanda del sistema de salud (urgencia, psiquiatria), del judicial y del SENAME.

A nivel delámbito escolar, los profesores detectan un $5 \%$ de niños maltratados.

- El maltrato infantil es un problema significativo en la población. Los estudios señalan una ocurrencia que va desde un $5 \%$ a un $13 \%$.

Si consideramos la utilización del castigo físico, los estudios nos señalan que entre el $50 \mathrm{al} 75 \%$ de los padres lo utilizan.

- En relación a las características de la víctima, la mayoría de las investigaciones coinciden en que:

En los casos de maltrato fisico, es mayor el porcentaje de niños afectados y en los casos de abuso sexual, el porcentaje mayor es de niñas.

En relación a la edad del agredido, aproximadamente el $80 \%$ ellos son menores de 12 años y casi un tercio de ese porcentaje, tiene menos de 5 años.

En el abuso sexual se señala que, cuando este es por un familiar, las victimas son menores y cuando es realizado por extraños, las víctimas son mayores.

- En lo relativo al agresor, la madre lo es en una proporción de (6:4), con respecto del padre. En los casos de abuso sexual, el total de los autores son hombres.

La edad del victimario se sitúa entre los 30 y 40 años.

- Factores asociados a la presencia de maltrato en los menores:

A nivel de la familia:

- Familias monoparentales o bien con padres sustitutos.

- Presencia de alcoholismo o problemas psiquiátricos en los padres agresores.

- Familias con gran número de hijos

- Desempleoy pobreza.

- Historia de violencia en los agresores.

${ }^{3}$ Los antecedentes de las investigaciones están basados en la revisión realizada en: Relaciones Familiares y Maltrato Infantil. UNICEF, 1997 de Larraín, S., Vega, J. y Delgado, $I$ 
En el año 1994, UNICEF realizó un estudio de prevalencia del maltrato infantil en una muestra representativa a nivel nacional de estudiantes de Octavo Básico; los principales resultados de dicha investigación se señalan a continuación:

Un 63\% de los encuestados respondieron que habian sido afectados por algún tipo de violencia fisica, de parte de sus padres. Un $14.5 \%$ había sido víctima de violencia psicológica y solamente un $22.5 \%$ no recibió violencia de sus progenitores. La violencia fisica se dividió en dos categorias, violencia fisica leve $(28.7 \%)$ y violencia fisica grave $(34.2 \%)$.

Los resultados nos permiten afirmar que en nuestra sociedad el uso del castigo físico con los niños constituye una conducta profundamente arraigada, que se da en todas las clases sociales y que la ejerce tanto el padre como la madre, aunque con mayor frecuencia es ésta quien la utiliza más. También podemos señalar que el maltrato produce un daño importante en el desarrollo emocional del niño y en sus relaciones familiares.

Tanto en la violencia psicológica, como en la violencia fisica leve y en la violencia fisica grave, el principal factor de riesgo es la presencia de violencia entre los padres. Cuando los padres tienen una relación de violencia, existe una alta probabilidad que los hijos sean víctimas de violencia grave. De estos resultados se desprende la necesidad de abordar el problema de la violencia en la familia, considerando las distintas manifestaciones. Por ejemplo, si conocemos una denuncia por maltrato de la mujer, hay una mayor probabilidad que los niños sean maltratados por la madre, por el padre o por ambos.

El tipo de estructura familiar aparece como un factor de riesgo, especificamente cuando la toma de decisiones no es conjunta. En otras palabras, la existencia de una estructura denominada "democrática" es un factor protector. Al contrario, una estructura "autoritaria" es un factor de riesgo para la violencia leve y grave.

El número de hijos aparece como un factor significativo de riesgo. Tanto el padre como la madre ejercen más violencia cuando mayor es el número de hijos, esto se explica por el estrés que esta situa- ción genera y la dificultad de los padres de desarrollar otras conductas en el control de los niños.

Respecto a las características del niño, los factores de riesgo tienen relación con la edad del niño, con la actividad que realiza y el rendimiento escolar. Los niños comienzan a ser golpeados antes que las mujeres. Son más golpeados los niños que trabajan, que aquéllos que no lo hacen y se maltrata más a los niños que tienen bajo promedio en el colegio.

\section{Consecuencias del maltrato en los niños.}

La violencia afecta distintas áreas del desarrollo cognitivo y emocional del niño. Los niños golpeados tienen problemas en las relaciones con sus padres, no se sienten amados por ellos y tienen menores grados de confianza. También presentan dificultades de rendimiento escolar y en las relaciones con sus compañeros de colegio. Son más tímidos en sus relaciones interpersonalesy poseen una mala relación con los hermanos.

\section{III.-Metodologia:}

Se diseñó un modelo comunitario para la implementación de un programa de detección y prevención del maltrato infantil desde el sistema escolar, en el que se consideraron las siguientes acciones:

3.1. Detección a través de los profesores deenseñanza básica deniños con sospecha o evidencia de maltrato infantil o abuso sexual.

Se diseñó un instrumento de detección de los siguientes tipos de maltrato: maltrato fisico, abandono fisico o negligencia, maltrato emocional y abuso sexual, el que fue aplicado por los profesores de primero a cuarto año de educación básica.

3.2. Los niños y niñas detectados por lo profesores con evidencia o sospechade lostipos demaltrato señaladosen el punto 3,1 , fueron evaluados, considerando la literatura sobre impacto del maltrato con las siguientes pruebas: 
- Cuestionario de resolución de problemas para niños, de G. Sepúlveda. En Somos personas. Sepúlveda; Larraín. 1997.

- $\quad$ Test de Depresión Infantil de M. Kovacs. (En: Cáceres, Collado, 1994).

- $\quad$ Test de apercepción Infantil de Bellaky Bellak CAT-H. (1991).

- Escala de autoconcepto de Piers-Harris (En Gorostegui, 1992).

3.3. Los padres detectados por los profesores con evidencia o sospecha de ejercer maltratoha cia sus hijos , en los tipos de maltrato señalados en el punto 3,1 , fueron evaluados con la prueba"Child Abuse Potential Inventory" (Bringiotti, M. et al. 1992)

3.4. Sediseñó un taller para niños víctimaso con sospecha de maltrato, desde un enfoque cognitivo, para mejorar la autoestima, la capacidad de identificar y expresar emociones, la capa cidad de empatía y formas de resolver conflictos sin violencia. Se aplicaron cuatro talleres de 24 sesiones cada uno. (Sepúlveda, Larraín, 1997).

3.5. Se diseño,un programa para padres maltratadores, paradesarrollar conductasquepermitan unaresolución no violentadeconfilictos. Se implementaron dostalleres desietesesiones cada uno.

3.6. Seevaluaron los cambios producidostanto en los padres como en los niños luego dehaber participado en el taller.

3.7. Sediseñó un programaparaprofesores, con el fin de capacitarlos para la reproducción de los talleres enumeradosen el pto. 3.3 y 3.4

\section{Talleres paraniños, padresy profesores}

\subsection{Taller paraniñosy niñas: "somos personas"}

Se realizaron cuatro talleres de 24 sesiones cada uno, de aproximadamente 10 participantes por taller.
Objetivos del taller:

- Desarrollar una buena autoestima.

- Capacidad de identificar y expresar emociones.

- Capacidad de empatía y toma de perspectiva.

- Resolución de problemas sin violencia.

El taller se organizó en cuatro etapas:

\section{Fase 1. Método Resolución de Problemas.} Conocimiento y comprensión.

(5 SESIONES: 1 A 5)

El objetivo de esta etapa es:

- Desarrollo de una Identidad positiva e integrada.

- Desarrollo de factores protectores y fortalezas individuales.

- Integración Grupal.

Fase 2. Método de Resolución de Problemas: BúsquedadeAltemativasy análisis deconsecuencias.

(SESIONES: 6a 12.)

El objetivo de esta etapa es:

- Reconocimiento y comprensión de sentimientos propios y de otros (Empatia y culpa).

- Consideración de necesidades e intereses propios y de las otras personas (Toma de perspectiva) en las relaciones sociales.

- Evaluación de consecuencias a nivel cognitivo y afectivo de sus expresiones emocionales, en síy en otros.

- Análisis del locus de control.

- Identificación de las responsabilidades personales en relación a los hechos relacionales (de la culpa, y de la ansiedad).

- Generan acciones de emociones y expresión alternativas a la agresividad y la violencia, en 
las relaciones interpersonales.

- Desarrollo de acciones prosociales.

- (Cooperación-Compartir),aumentando la iniciativa y autoconfianza.

Fase 3 : Método de Resolución de Problemas: Planificación, (Plan de acción).

(5 SESIONES: 13 a 17 .)

El objetivo de esta etapa es:

- Identificación, comprensión y valorización del respeto mutuo las relaciones humanas.

- Identificación, comprensión y valorización de la responsabilidad mutua en las relaciones humanas.

- Identificación, comprensión y valorización de la justicia en las relaciones interpersonales.

- Análisis de antecedentesy consecuencias de las acciones, considerando las necesidades, intereses, sentimientos y valores (Propios y de otros).

- Elaboración de planes de acción para satisfacer nuestras necesidades, deseos, y los de otros.

- Búsqueda de mediosy pasos para llevar a cabo el plan.

\section{Fase 4: Integración. Método de Resolución de Problemas.}

\author{
(Sesiones 18 a la 24) \\ El objetivo de esta etapa es:
}

- Integración de pasos del método de resolución de problemas interpersonales.

- Aplicación a situaciones problemas de los niños con sus familiares, en la escuela (con profesores y compañeros) y con sus amigos.

\subsection{Taller para Padres: "CreciendoJ untos"}

El taller para padres se organizó en siete sesiones, cuyos objetivos son:
- Potenciar a través de una actividad grupal, el fortalecimiento de habilidades de los padres para el cuidado de sus hijos. De modo de lograr una comunicación ajustada, no violenta, que posibilite el desarrollo normal del niño.

- Sensibilizar a los padres y cuidadores de las cualidades positiva de sus hijos favoreciendo sentimientos empáticos.

- Favorecer la capacidad de detectar y comprender las necesidades de los niños, ayudándolos a establecer relaciones de confianza con los adultos.

- Fomentar el deseo de los padres de aprendery profundizar en la temática de las relaciones familiares.

- Contribuir a establecer un clima de confianza para que las familias puedan percibir la escuela como un espacio de apoyo en su rol educador.

- Coordinar pautas de actuación educativas entre la escuela y la familia, de modo de tener una congruencia en las pautas de crianza en ambas organizaciones.

Los padres que asisten al taller "creciendo juntos" tienen un repertorio extenso de habilidades de cuidado con sus hijos, estas son activadas en relaciones y situaciones particulares. El taller pretende apoyar y fortalecer la existencia de habilidades positivas de los criadores y no reemplazar sus habilidades por otras que puedan aparecer ajenas o extremas.

Se proponen tres pasos a seguir a lo largo de las sesiones:

- Realizar un diagnóstico que parta de las propias vivencias y experiencias de los padres. Partiendo de los conocimientos, actitudes y experiencia de los propios padres, esto posibilita el ir generando nuevos conocimientos. Dentro de las técnicas para lograr esto estálluvia de idea, foros, role- playing, etc

- Entregar información que permita ir incorporando nuevos conocimientos que favorezcan la comunicación entre los padres y de éstos con sus hijos. Se pueden combinar exposiciones, 
con cuentos, métodos visuales, recortes de diarios, articulos etc

- Valorar lo que se ha realizado, reconocer los avances y ver la aplicabilidad de lo adquirido en el taller en las relaciones con sus hijos.

\section{3.-Taller para profesores}

El taller para profesores tiene por finalidad que los docentes (mayoritariamente los orientadores), desarrollen las destrezas para reproducir el programa en el colegio. Se trabajó con cinco escuelas municipalizadas, más una particular subvencionada, un centro de padres y un Jardin Infantil de la JUNJI, haciendo un total de 7 establecimientos.

En la capacitación se entregaron los siguientes contenidos en ocho sesiones:

- Conocer la Convención Internacional de los Derechos del Niño y la Realidad de la Infancia en Chile y la necesidad de compatibilizar ésta con la necesaria disciplina escolar.

- Realizar un autodiagnóstico de la relación profesor-alumno en el aula.

- Trabajo con un instrumento para detección de niños con problemas de violencia en su espacio familiar.

- Adiestramiento para una intervención en crisis y derivación en aquellos casos que se detecten de maltrato infantil.

- Adiestramiento para trabajo con niños en situación de riesgo y con niños en general.

- Adiestramiento en un taller para padres, orientado a estimular pautas de crianza no violen- tas, utilizando la metodología de resolución no violenta de conflictos.

- En una segunda etapa se ofrece un taller de: Métodos De Resolución no Violenta de Conflictos en la Sala de Clases.

\section{5.-Resultados}

\subsection{Niños Detectados por Maltrato o Sospecha.}

De un total de 320 niños y niñas que cursaban (1995) entre primero y cuarto año básico, se detectaron 65 niños maltratados o con sospecha de maltrato.

Se detectaron un $20 \%$ de los niños. Un $62 \%$ son hombres y un $38 \%$ mujeres. Un $57 \%$ son de $1^{\circ}$ y $2^{\circ}$ básico y un $43 \%$ de $3^{\circ}$ y $4^{\circ}$.

En relación a los tipos de maltrato, los resultados se observan en la Tabla 1.

Existen niños que presentan más de un tipo de maltrato. Es frecuente el maltrato fisico junto al maltrato emocional. Hay niños que presentan negligencia y maltrato fisico y emocional. En relación al abuso sexual hay consenso entre los profesores que es muy dificil su detección y que requiere un adiestramiento especial.

Hay diferencias en las manifestaciones de maltrato según el sexo y el curso de pertenencia de los niños.

En relación al sexo, se detecta un número mayor de niñas con maltrato fisico y emocional, no

Tabla 1.-

Tipos de Maltrato

\begin{tabular}{lccccccccc}
\hline Maltrato & \multicolumn{1}{c}{ M. fisico } & \multicolumn{2}{c}{ Negligencia } & \multicolumn{2}{c}{ Abuso sexual } & \multicolumn{2}{r}{ Maltrato Emocion } \\
& $\mathrm{N}$ & $\%$ & $\mathrm{~N}$ & $\%$ & $\mathrm{~N}$ & $\%$ & $\mathrm{~N}$ & $\%$ \\
& 16 & 25 & 32 & 49 & 62 & 95 & 23 & 35 \\
Ausencia & 16 & 33 & 51 & 3 & 5 & 42 & 65
\end{tabular}


existiendo diferencias en relación a la negligencia.

Los cuatro casos en donde hay sospecha de abuso sexual son de sexo masculino y de primero bási$\mathrm{co}$, sin embargo el número no permite sacar conclusiones.

Se detecta un mayor número de niños con maltrato emocional en tercer y cuarto año, y mayor maltrato físico en los niños de primero y segundo año. Negligencia se detecta significativamente más en primer año, si se les compara con segundoy cuarto.

El abuso emocional se detecta solamente en los niños de primero básico.

Es importante señalar que las diferencias por curso pueden tener su origen en que la detección la realizan distintos profesores y no en las diferencias reales de tipos de maltrato.
5.2. Evaluación Psicológica de los Niños con Sospecha De Maltrato.

Se señalaran los resultados de la evaluación de aspectos del desarrollo afectivo-social realizada a través del CAT-Hy las otras pruebas. Se señalaran sus resultados comparando los puntajes antes y después del taller para niños. Es importante señalar que no se encontraron diferencias significativas por sexo en las diferentes variables estudiadas.

5.2.1. Características afectivo- sociales de los niños victimas de maltrato evaluados a través del CAT- H. (65 niños entre 6 y 11 años) La mayoria de los sujetos presentan imágenes familiares, de pares y de otros adultos significativos y de sí mismo de tendencia negativa (Tabla 2).

Las relaciones familiares y sociales son mayoritariamente insatisfactorias, especialmente las relaciones maternales y parentales (Tabla 3).

\begin{tabular}{|lcccccc}
\hline \multicolumn{7}{c|}{$\begin{array}{c}\text { Tabla2.- } \\
\text { Distribución de Imágenes. }\end{array}$} \\
\hline Imágenes & $\begin{array}{c}\text { Simismo } \\
\%\end{array}$ & $\begin{array}{c}\text { MATERNA } \\
\%\end{array}$ & $\begin{array}{c}\text { PATERNA } \\
\%\end{array}$ & $\begin{array}{c}\text { FRATERNA } \\
\%\end{array}$ & $\begin{array}{c}\text { DEPARES } \\
\%\end{array}$ & $\begin{array}{c}\text { OTROS } \\
\text { SIGNIFIC } \\
\%\end{array}$ \\
\hline $\begin{array}{l}\text { Negativa } \\
\text { Predominio }\end{array}$ & 35 & 34 & 34 & 29 & 32 & 35 \\
$\begin{array}{l}\text { Negativa } \\
\text { Predominio }\end{array}$ & 35 & 48 & 40 & 32 & 35 & 37 \\
$\begin{array}{l}\text { Positiva } \\
\text { Positiva }\end{array}$ & 28 & 18 & 20 & 19 & 25 & 26 \\
\end{tabular}

\section{Tabla3.}

Distribución de Relaciones

\begin{tabular}{lcccc}
\hline RELACIONES & MATERNAL & PATERNAL & FRATERNAL & INTERPERSONAL \\
\hline INSATISFACTORIA & 72 & 65 & 55 & 48 \\
PARCIALMENTE & 23 & 23 & 20 & 42 \\
SATISFACTORIA & 5 & 12 & 5 & 11
\end{tabular}


En relación a la satisfacción o insatisfacción de las necesidades planteadas por Maslow, se encuentra que las necesidades básicas, de protección y la de pertenencia y afecto son las que aparecen con una mayor frecuencia de insatisfacción en la muestra de niños (tabla 4)

\begin{tabular}{|lcc|}
\hline \multicolumn{3}{|c|}{ Tabla4 } \\
\hline Distribución de Insatisfacción de & Necesidades \\
\hline Necesidades & Frecuencia & $\%$ \\
Básicas & 38 & 58 \\
Protección & 52 & 80 \\
Pertenencia & & \\
y afecto & 57 & 88 \\
Autoestima & 31 & 48 \\
Autorrealización & 13 & 20 \\
\hline
\end{tabular}

Esto puede relacionarse con la expresión de las emociones básicas, (rabia, tristeza, miedo, alegria, afecto), la que en la mayoria de los niños es insatisfactoria $(92 \%)$, siendo la tristeza la emoción que se manifiesta con mayor frecuencia en los niños (90\%), seguida por el miedo (75\%).

En relación a los tipos de maltrato, hay diferencias significativas en la expresión emocional, observándose con mayor frecuencia una expresión insatisfactoria en los niños con maltrato emocionaly negligencia, que en los niños con maltrato fisico.

En relación al control de impulsos, se aprecia que la mayoria de los niños tienen un bajo control de impulsos (Tabla 5).

\begin{tabular}{|ccc|}
\hline \multicolumn{3}{c|}{ Tabla5 } \\
Control de Impulsos \\
\hline CONTROL & FRECUENCIA & $\%$ \\
IMPULSIVO & 55 & 85 \\
REFLEXIVO & 10 & 15 \\
\hline
\end{tabular}

Desde un enfoque cognitivo del desarrollo, nos interesó observar como se van articulando los diferentes aspectos señalados del desarrollo afectivo- social, en la construcción de las organizaciones de personalidad de los niños. Con este objetivo utilizamos las formas de organización de significado personal de Guidano (1987), a través de las cuales podemos analizar como el niño construye la realidad con una forma de procesamiento o sistema de conocimiento, la cual tiene una determinada tonalidad afectiva, relacionada con las experiencias vinculares tempranas: depresiva, fóbica, obsesiva, desorganizada (o dapica).

En la organización de significado depresiva, hay vivencia de abandono o pérdida afectiva, sin un apego seguro, generados por la desatención y/o el rechazo de adultos significativos. En la organización fóbica, se vivencia un vinculo afectivo ansioso, y un mundo amenazante y hostil. En la organización dapica, el vinculo es ambiguo, indefinido y contradictorio; $y$ en la organización obsesiva el vinculo es ambivalente, vivenciando una actitud de rechazo de los adultos significativos (Tabla 6).

\begin{tabular}{|c|c|c|}
\hline ORGANIZACION & FRECUENCIA & $\%$ \\
\hline DEPRESIVA & 31 & 48 \\
\hline FOBICA & 14 & 22 \\
\hline OBSESIVA & 8 & 12 \\
\hline DAPICA & 12 & 18 \\
\hline TOTAL & 65 & 100 \\
\hline
\end{tabular}

Existe un predominio claro de organización de significado personal depresiva, sin presentarse vinculos seguros con los adultos significativos. Estas organizaciones de significado muestran un predominio de vivencias de vinculos afectivos inseguros e inestables, los que se reflejan en las imágenes de mundo que entregan los niños, la cual muestra la percepción de sí mismo, de los demás y del ambiente del niño (Tabla 7).

Se puede observar que la imágen de mundo predominante es negativa (72\%), siendo la de mayor frecuencia entre éstas la nihilista, en la cual el sí mismo y la realidad es percibida como negativa, lo 


\begin{tabular}{|lcc|}
\hline \multicolumn{3}{c|}{ Tabla7 } \\
Imagen de Mundo. \\
IMAGEN & FREC. & $\%$ \\
Negativa Nihilista & 36 & $55 \%$ \\
Negativa Paranóica & 8 & $12 \%$ \\
Negativa Depresiva & 3 & $5 \%$ \\
Realista & 6 & $9 \%$ \\
Idealista & 9 & $14 \%$ \\
Discordante & 3 & $5 \%$ \\
TOTAL & 65 & $100 \%$ \\
\hline
\end{tabular}

cual se relaciona con problemas tanto de insatisfacción personal como de ajuste al medio en la edad juvenil (Almonte y otros, 1983, 1990; Sepúlveda, G., 1991; Sepúlveday otros, 1991).

5.2.2.- Cambios en las variables de autoestima, depresión y resolución de problemas, antes y luego de la participación en el taller "Somos Personas", diseñado con la metodología de resolución de problemas interpersonales".

Los niños y niñas participantes en el taller, se presentan en la tabla 8.

Las razones de la deserción en orden de importancia fueron las siguientes:

1.- Padres no autorizan por pérdida de clases

2.- Retiro de la Escuela

3.- Enfermedad

\section{a) Autoestima}

De acuerdo a la Escala de Autoconcepto de PiersHarris los resultados en los niños y niñas con evidencia o sospecha de maltrato señalan que un $9.6 \%$ de los niños tiene un puntaje muy bajo. Un $43.1 \%$

\begin{tabular}{|lcccc|}
\hline \multicolumn{5}{c|}{ Tabla8. } \\
Participación en el Taller \\
CURSO & $\mathrm{N}^{\circ}$ INSCRITOS & $\mathrm{N}^{\mathbf{0}}$ INICIAL & $\mathrm{N}^{0}$ FINAL & \% DESERCIÓN \\
PRIMERO & 21 & 20 & 18 & 10 \\
SEGUNDO & 16 & 15 & 12 & 20 \\
TERCERO & 16 & 14 & 10 & 29 \\
CUARTO & 18 & 16 & 14 & 12,5 \\
TOTAL & 71 & 65 & 54 & \\
\hline
\end{tabular}

\begin{tabular}{|lcc|}
\hline \multicolumn{3}{|c|}{ Tabla9 } \\
Categorías del Nivel deAutoestima \\
& Pre- taller & Post taller \\
Categorias & porcentaje & porcentaje \\
Alto & $32 \%$ & $58 \%$ \\
Promedio Alto & $26 \%$ & $32 \%$ \\
Promedio & $37 \%$ & $5 \%$ \\
Promedio Bajo & $0 \%$ & $\% \%$ \\
Muy Bajo & $0 \%$ & $\% \%$ \\
\hline
\end{tabular}

esta bajo el puntaje promedio de los niños de estratos socio-económicos bajo y un $56.9 \%$ esta sobre el promedio. Ningún niño alcanza el puntaje mayor.

La muestra para evaluar las variaciones en autoestima estuvo constituida por 19 niños y niñas entre primero y cuarto medio, en los que solamente se sospechara de un tipo de maltrato (Tabla 9).

Existen cambios significativos en los puntajes antes y después de la participación del taller (20.5 $<35$ )

Al evaluar el efecto de la intervención en los niños que en la primera evaluación presentan una 
autoestima igual o inferior al promedio ( $42 \%$ de la muestra), el impacto del taller es mayor.

\section{b) Depresión.}

La muestra estuvo constituida por 24 niños y niñas, mayores de 7 años y 6 meses.

El $50 \%$ de los niños con sospecha de maltrato se sitúan en el tercio superior del puntaje de depresión (alto). Luego de la intervención se mantiene este nivel, pero disminuye el Tercio medio, sin embargo la diferencia no es significativa antes y después de la participación del taller.

Al analizar el cambio en los niños y niñas que presentan un puntaje mayor en la escala de depresión (mayor depresión), si se observa un cambio significativo luego de la participación en el taller.

\section{c) Resolución DeSituaciones Problema.}

En relación a las habilidades de resolución de problemas, evaluadas a través del Cuestionario de resolución de problemas para niños (Tabla 10), se observa que la mayoría de los niños no logran en la evaluación pretratamiento las diferentes habilidades de resolución de problemas: reconocimiento de problemas, generar soluciones alternativas, anticipar consecuencias y pensamiento orientado a metas. En la evaluación después del taller, se aprecia un avance significativo, aumentando los niños sus habilidades cognitivas de resolución de problemas interpersonales, y disminuyendo la elección de alternativas violentas para la solución de conflictos.
En relación a las etapas de desarrollo cognitivo de estrategias de negociación interpersonal o de resolución de problemas (Selman y Schultz, 1988, en Wenar, 1994), se puede observar en la tabla 11, que los niños al iniciar el taller se encontraban mayoritariamente en la primera etapa, impulsiva, en la cual las estrategias de resolución de problemas son principalmente a través de conductas de agresividad fisica o evitación. Un porcentaje menor se encontraba en la etapa unilateral, en la cual el niño actúa defendiendo sus intereses y su punto de vista, y se acomoda según quién tenga más poder o fuerza.

En este sentido se aprecia un cambio evolutivo muy significativo en las etapas de resolución de problemas, hacia la etapa unilateral y autoreflexiva, en la cual las estrategias se basan en intercambios reciprocos, con una consideración del punto de vista del otro, y conductas de tipo persuasivo y deferentes. Aún no se logran estrategias más de tipo cooperativo, lo cual se relaciona con la etapa de desarrollo de los niños.

En las etapas de desarrollo moral según Kohlberg (1984), se observa asimismo en la tabla 12 , un cambio evolutivo significativo después del taller, con avances desde etapas preconvencionales, en las cuales se actúa correctamente para evitar el castigo, hacia posturas preconvencionales de nivel superior, en las cuales se actúa según necesidades e intereses propios, pero reconociendo los intereses de otros, y realizando intercambios de favores. Se observa además un porcentaje significativo de ninos en etapas convencionales, en las cuales se actúa para manener las normasy la autoridad, logran-

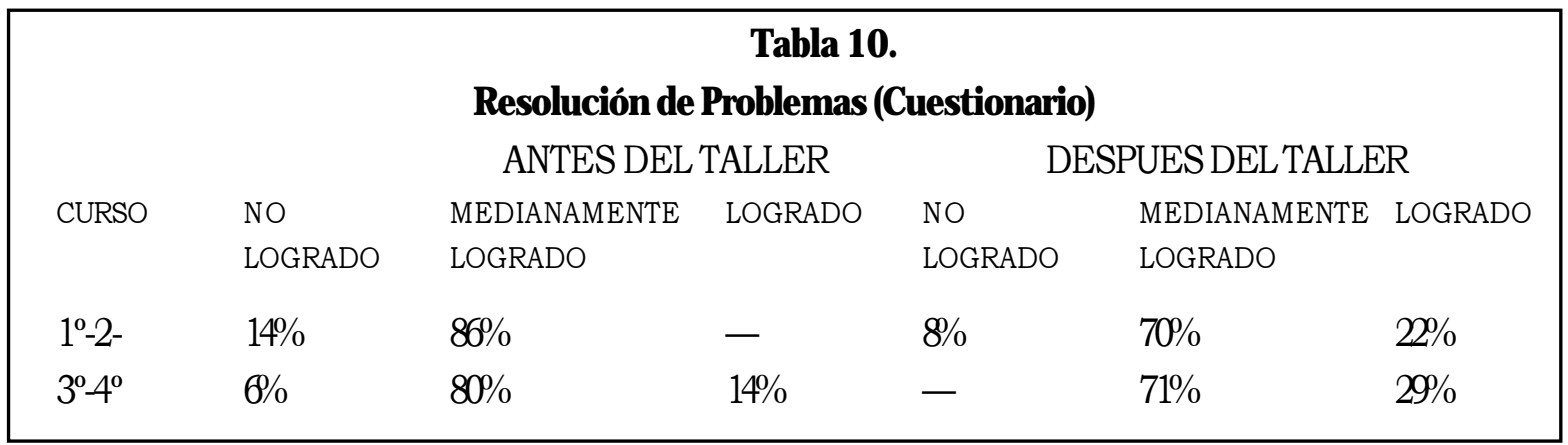




\section{Tabla11.-}

\section{Etapas de Resolución de Problemas (Selman y Schultz).}

ANTES DEL TALLER

DESPUESTALLER

\begin{tabular}{|c|c|c|c|c|c|c|}
\hline CURSO & IMPULSIVA & UNILATERAL & AUTOREFLEXIVO & IMPULSIVO & UNILATERAL & AUTOREFLEXIVO \\
\hline $1^{o}-2^{o}$ & $94 \%$ & $6 \%$ & - & - & $77 \%$ & $13 \%$ \\
\hline $3^{0}-4^{0}$ & $78 \%$ & $22 \%$ & - & - & $43 \%$ & $57 \%$ \\
\hline
\end{tabular}

\section{Tabla12.-}

Etapas de Desarrollo Moral (Kohlberg, 1984).

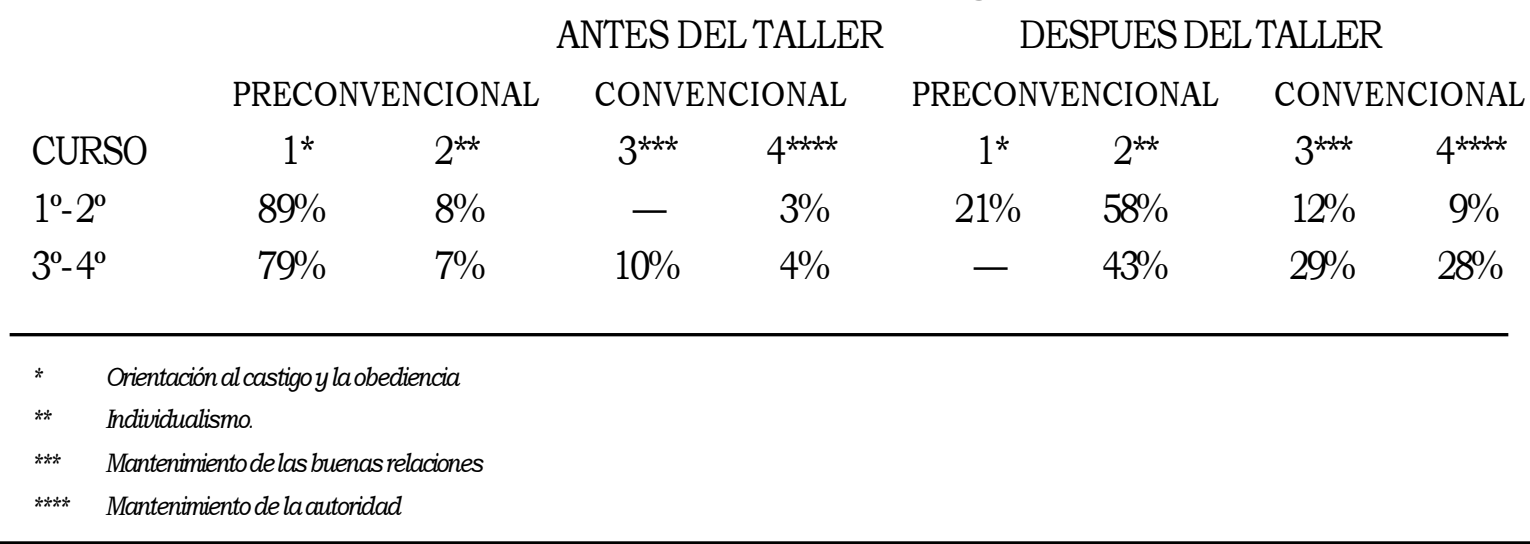

do actuar según expectativas mutuas, y realizar acuerdos interpersonales.

\subsection{Evaluación de los Padresen queexistesos- pecha oevidenciademaltrato hacia sus $h i j o s$.}

5.3.1.Comparación Psicométrica Pre-PostIntervención delTaller de Padres.

Se utilizó la prueba de "Child Abuse Potential Inventory" para evaluar los cambios producidos en los padres luego de participar en el taller.

a.Los padres con sospecha de maltrato son evaluados por la escala como de alto riesgo de cometer maltrato en un $95 \%$ de los casos.

b.Se aplicó la escala "Child Abuse Potential Inventory" a 14 padres que asistieron al taller y a 14 padres con puntajes que los sitúa como de alto riesgo y se comparó con los puntajes obtenidos a los 6 meses (Tabla 13).
El grupo experimental (los padres que participaron en el taller) muestran diferencias significativas en el puntaje de la prueba "Child Abuse Potential Inventory" antes y después de la participación en talleres. El grupo control (padres con sospecha de maltrato, que no intervienen en el taller) mantienen su puntaje al cabo de seis meses.

\subsection{Evaluación cualitativa de los profesores que asisten al taller}

La evaluación por parte de los capacitadores señala:

Se evalúan positivamente las actividades planteadas en las siete sesiones del taller, sin embargo, se considera que la imaginería es una técnica sobre la cual no tienen un manejo de su impacto. En base a esta afirmación, se plantea la necesidad de supervisión durante el transcurso del taller. 
Tabla13.-

Comparación de los puntajes obtenidos en la escala deabuso
por el grupo experimental y el grupo control.

EVALUACIÓN

EVALUACIÓN

PRE-INTERVENCIÓN

EVALUACIÓN

POST- INTERVENCIÓN
GRUPO CONTROL

PROMEDIO T DE STUDENT

254.714

0.08

256.143
GRUPO EXPERIMENTAL

PROMEDIO

T DE STUDENT

309.785

5.18

157.642
Se propone aumentar a 10 las sesiones, de modo de tratar tres unidades centrales: Nociones básicas sobre el problema del maltrato, conocimiento experiencial de las actividades que implica el taller "somos personas" y comprensión de la metodologia y cambio que se utiliza, de modo de no limitarse a las actividades señaladas en el manual.

En base a la evaluación de la implementación del proyecto en La Comuna del Bosque, se propone ejecutar el proyecto en las siguientes fases:

\section{1.- Capacitación de los profesores.}

Detección de situaciones de maltrato

Taller de prevención con niños

Taller de prevención con padres

Metodología de evaluación

2. Detección y reclutamiento de padres que participarán en los talleres. Se propone la realización de una convocatoria amplia, donde sean incluido todos los padres (no solamente los con sospecha de maltrato. El taller, por las características de la temática a tratar debe ser voluntario.

3. Para la realización de los talleres debiera existir un profesional que realice la supervisión a los profesores

\section{6.- Conclusión}

El programa descrito propone un modelo interdisciplinario de detección, evaluación, prevención y atención de niños y niñas con evidencia o sospecha de maltrato y de su grupo familiar.

Se pretende desarrollar una metodología y materiales de trabajo para posibilitar la implementación de la intervención desde los docentes y orientadores de los colegios, los que deben de contar con el apoyo institucional de la municipalidad y de la comunidad escolar.

Se diseñaron y evaluaron positivamente los siguientes materiales:

a) Pauta de detección de maltrato infantil,

b) Taller somos personas, para ser aplicado con niños de primer ciclo básico.

c) Taller "creciendo juntos", para ser aplicados a padres

d) Material de capacitación a profesores "Apresto para la ejecución de un taller para padres destinados a la prevención de maltrato infantil intrafamiliar".

La evaluación de los talleres permite concluir:

a) Luego de la realización del taller en los niños, se evidencia un mejoramiento de la autoestima, menores niveles de depresión, mejoramiento de las capacidades para resolver problemas y cambio en las etapas de resolución de problemas interpersonales, y de las etapas de desarrollo moral del estadio preconvencional uno, a los niveles preconvencional dos y convencional.

b) Se concluye que para evaluar el impacto del 
maltrato,el uso de pruebas psicológicas en la linea cognitiva, como el Test de apercepción temática infantil (CAT H), permite la observación del desarrollo en sus diferentes aspectos, entregando una visión de la imagen de si, de otros y del mundo del niño, también la prueba de resolución de problemas, entrega información respecto a los estilos de resolución de problemas interpersonales, ya sea impulsivos o reflexivos.

c) El uso de cuestionarios autoadministrados presenta problemas de confiabilidad, especialmente en niños menores, además tienden a responder en forma concreta, centrándose en su situación presente inmediata.

d) Se evaluó los cambios producidos en el taller de los padres, obteniéndose un puntaje significativamente menor en la prueba "Child Abuse Potential Inventory" antes y después de la participación en talleres.

e) Se considera que siguiendo los pasos establecidos en el proyecto, es posible desarrollar un programa preventivo de maltrato infantil en la comunidad, partiendo desde el sistema escolar, en donde los profesores, previamente capacitados tienen un rol de liderazgo en el trabajo con niños y padres. El trabajo desde la escuela implica trabajar paralelamente el tema de la violencia institucional.

\section{Bibliografia}

Almonte, Sepúlveda, Avendaño, Valenzuela. (1983) Desarrollo psicosocial de adolescentes de 12 a 15 años, del áreanorte de Santiago. Revista Chilena de Pediatria. Vol 56 Nº 4 Julio-agosto.

Almonte, Sepúlveda, Valenzuela, Avendaño. (1990) Desarrollo psicosocial de adolescentes de 16 a 19 años. Revista de Psiquiatría, Año VII N ${ }^{\circ} 2$.

Barudy,J . (1998) El dolorinvisible de lainfancia. Paidós Terapia Familiar. Buenos Aires.

Bellak, L; Bellak, S. (1991). Test de apercepción infantil, con figuras humanas. Manual. Editorial Paidós, Buenos Aires.

Bringiotti, M. etal. (1992). Adaptación y validación del Child abuse potential inventory -CAP. Versión preliminar para la Argentina. Subsecretaria de investigaciones. Facultad de Psicologia, Buenos Aires, Argentina.
Cáceres C., Collado R. (1994). Estandarización del cuestionario de depresión infantil de M. Kovacs. Tesis, Universidad Diego Portales, Santiago, Chile.

Cirillo, Di Blasio. (1991) Niños maltratados. Diagnóstico y terapia familiar. Ediciones Paidos, Buenos Aires.

Gracia,Musitu.(1993). El maltrato infantil. Un análisis ecológico de los factores de riesgo. Ministerio de Asuntos Sociales .España.

Cantón, Cortés. (1997). Malos tratos y abuso sexual infantil. Siglo XXI de España Editores, S.A.

DePaúl, Amuabarrena.(1997) Manual de protección infantil. Masson. Barcelona.

Gorostegui, M. (1992) Adaptación y construcción de normas de la Escala de autoconcepto para niños de Piers y Harris. Tesis, Universidad Católica de Chile, Santiago, Chile.

Guidano, V. (1987). Complexity of the self. The Guilford Press, USA.

Kempe, Kempe. (1985). Niños Maltratados. Ediciones MORATA, S.A. MADRID.

Kohlberg, L. (1984) Psicología del desarrollo moral. Desclee de Brower, Bilbao, España, 1992.

Larrain,S.(1997). Relaciones Familiares y Maltrato Infantil. Editorial Cal\&Canto. Unicef Chile

Larrain,S. (1994). Violencia Puertas Adentro. La situación de la mujer en Chile. Ed. Universitaria. Chile

Martinez, de Paúl.(1993) Maltrato y abandono en la infancia. Ediciones Martinéz Roca, S. A. Barcelona.

Miller, A.( 1985) Por tu propio bien. Raíces de la violencia en la educación del niño. Tusquets Editores. Barcelona.

Sepúlveda, G. (1991). Desarrolo psicológico en la edad juvenil. En Desarrollo normal y trastornos psicosociales en la edad juvenil. Serie cientifica médica, Centro de extensión biomédica, Facultad de Medicina, Universidad de Chile.

Sepúlveda, Almonte, Valenzuela, Avendaño. (1991). Estilos de socialización delos padres ydesarrollo psicosocial en adolescentes de 16 a 19 años. Revista Chilena de Pediatría 62 (6).

Sepúlveda, G.; Larraín, S. (1997) Somos personas. Departamento de Psicologia, Facultad de Ciencias Sociales, Universidad de Chile.

Wenar, Charles. (1994) Developmental psychopathology. Frominfancy throughadolescence. Mc. Graw Hill, Inc. USA. 